\title{
The Field as Labyrinth: Exploring Ethnographic Practices through the Works of Jorge Luis Borges
}

\author{
By Sarah Rae Osterhoudt (Yale University)
}

The brilliant short stories of the Argentinean author Jorge Louis Borges echo many of the themes raised through the ethnographic encounters of practicing anthropologists. Through the exploration of such questions as identity, memory, language, commensuration and human relationships, the characters invented by Borges continuously navigate new physical and intellectual landscapes. The following paper draws from several of Borges' short stories, outlining how their themes and characters present useful allegories for scholars interested in exploring ethnographic imaginations. As an "armchair ethnographer," Borges' preoccupation with human endeavors towards greater understanding thus provides a unique and creative lens through which to consider the practical and ethical questions of ethnographic enterprises.

\section{Introduction}

"Now I held in my hands a vast methodical fragment of an unknown planet's entire history, with its architecture and its playing cards, with the dread of its mythologies and the murmur of its languages, with its emperors and its seas, with its minerals and its birds and its fish, with its algebra and its fire, with its theological and metaphysical controversy."

$$
\text { - Jorge Luis Borges }{ }^{1} \text {, Tlon, Uqbar, Orbis Tertius, p7 }
$$

As illustrated by the other papers included in this volume, questions of ethnographic practice and representation are still forefront within the field of anthropology, and are intertwined with how we think about both our work and the discipline more generally. In the following paper, I would like to add another character into the discussion - the brilliant Argentinean writer Jorge Louis Borges. I will draw upon some of his short stories, and consider how the scenarios they describe may be useful to practicing anthropologists as allegories for navigating both the practice of fieldwork and the experience of writing up field data. Overall, I will present an analysis from four of Borges' fictional stories as offering interesting allegories in facing the challenges of ethnography. These four stories echo four of the experiences of the anthropologist: from first encountering field sites, to grappling with data; from writing up notes, to keeping the intensity of the field in the forefront of our minds, even when we are sitting far away in academic offices.

Particularly helpful in understanding ethnographic practices is the metaphor of labyrinths that Borges implements in many of his stories - mazes that baffle and mislead the characters in his stories, even if they think they understand the events unfolding around them. Currently, in my own experience as a doctoral student in anthropology, I was at first tempted to consider the 
academic experience as more or less a linear process: one completes coursework, then conducts fieldwork, then returns to the university to analyze and write up what she has learned. Now immersed in my own field research, however, I recognize that the process is more circular, involving much doubling back and reevaluation. Often, the path of fieldwork may seem clear at first, until one encounters a wall of the labyrinth that blocks one's view. Staring at the wall, one wonders: What assumptions did I make at first that now seem misguided? How can I back up, re-trace my steps, and try a different path? Overall, the metaphor of the field as labyrinth may be useful to re-conceptualize the experience of the anthropologist, as she constantly navigates a winding path between theory, participation, observation, and writing.

Borges, born in 1899, is in many ways an ideal author to teach us about the personal and epistemological dilemmas encountered by the ethnographer. Throughout his life, Borges wrote short stories that grappled with the fundamental questions of understanding and representing reality. The questions haunting him also may often haunt those immersed in ethnographic enterprises, as they approach and portray the communities in which they work.

Taking a historical perspective on the discipline of anthropology, one encounters the debates during the early twentieth century between an "armchair" approach to anthropology, which drew from the observations of others to deduce theories, and the more empirical approach to anthropology, which recorded first-hand observations of "subject" communities. The notion of an "armchair" anthropologist was derived from the so-called armchair rationalist philosophers, epitomized by Descartes, who deduced universal truths by building upon initial suppositions, without empirical investigation.

Borges, I propose, may be considered to represent, not an armchair anthropologist per se, but rather an armchair ethnographer. The stories of Borges, as James Irby points out in his preface to Labyrinths, "create, outside time and space, imaginary and symbolic worlds." (ix) Within these textured and imagined worlds, Borges fixates on one idea, usually a bizarre paradox, conflict, or contradiction. Unencumbered by the myriad of obstacles and ethical concerns that face ethnographers of real communities, Borges is able to explore many angles of the situation, drawing them out to their extreme conclusions. In this sense, he can be seen to create social thought experiments, much as philosophers propose their own logical thought experiments. In his stories, Borges thus embraces paradox and contradiction as areas that shed light on the true nature of substances. His stories, as Irby notes, "are always concerned with the process of striving which lead to discovery and insight." (xviii) These themes of contradiction, of striving for insight, and of separating illusion from reality are also present in anthropological fieldwork.

There exist other rationales for using a literary source to understand issues of ethnography. Debates over just how literary ethnographies should become have been swirling around anthropology for a long time, especially with the "literary turn" of anthropology in the post World War II era, as well as the "crisis of representation" of the 1980s (Clifford 1986). In these projects, culture was public, encased in symbols, and semiotic. As such, going to the field emerged as navigating a network of interpretations - a web of meanings (Geertz 1973). This disciplinary turn broadened the rubric of "the field" while shifting it to emphasize the crucial connections between fieldwork and writing ethnography (Marcus and Cushman 1982). Writing 
for anthropologists assumed a more central place within this version of what constituted fieldwork.

While I will not directly address the place of literary writing within actual ethnographic writeups, I do believe that looking towards literature may assist social scientists in thinking about their own practice. Anthropology remains perched between the humanities and the sciences, which offer anthropologists unique opportunities to draw insights from both realms. Exploring other forms of writing may, for example, provide insights into techniques of crafting narrative structure and character development - areas important for anthropologists to explore when formulating their own ethnographic style and voice. While this paper looks towards Borges as one potential literary guide through anthropological practices, there are undoubtedly many other authors that offer their own inspiration and allegories. In this sense, it may be productive to pack a favorite novel or volume of poetry when embarking on field research.

\section{Methodological Disclaimers}

Before moving to the stories of Borges, I first offer a few methodological caveats. First, as I explore realms of literary analysis sources, I will, much like ethnographers themselves, be largely navigating through unfamiliar territory. Unschooled in literary theory and frameworks of analysis, my goal is not to discover new insights into the complicated works of Borges. Instead, I will use his anecdotes to offer some allegories for anthropology that have proved useful for my own experience as a student of anthropology. Overall, in the following discussion I will focus on this idea of allegory - outlining ways on how the stories of Borges may help us relate to the challenges of ethnography.

The methodology presents a second important caveat: the problem of rifling through highly textured stories with a preconceived final objective in mind. The short excerpts I take from Borges represent only a small fragment of his larger works. There are many of Borges' stories which I did not include but that could be interesting for this discussion. A hundred people each reading the same Borges story a hundred times would likely come up with a different applicable quote and context every time. It is a situation I imagine Borges himself would appreciate.

Many other scholars from a wide variety of social science disciplines have also drawn upon the works of Borges in their own projects. In his work The Order of Things (1994), for example, Foucault makes several references to the works of Borges, including the story of Funes with his perfect memory - a story I also visit in the context of conducting ethnography. Similarly, Fernando Coronil (2001) draws from the Borges story describing the existence of a perfectly accurate map, which unfortunately is also drawn at a 1:1 scale ${ }^{2}$. Environmental anthropologists Sivaramakrishnan and Agrawal (2003) open their book on regional modernities with a quote from Borges's A Personal Anthropology. The fact that Borges is cited within the social sciences does not, in my opinion, prohibit other people engaged in academics from reading and gleaning insight from his stories. Rather, along with other classics within the social sciences and beyond, the works of Borges merit re-visitations and context-specific interpretations. 


\section{Conceptions of the Field}

There exists a tendency within anthropology to reify the notion of "the field," and the notion of "going to the field" has long held a special place in the collective imaginations of students (Sanjek 1990). Anthropologists often speak of "going off to the field" or "coming back from the field" in a manner that implies there exists a shared understanding of what constitutes such a "field." Over the course of anthropology's history, however, what was considered emblematic of the "field" has morphed and shifted along with the changing theories, politics, technologies, and ethical questions of the time (Ortner 1984). Today, for example, the "field" may be a World Bank office in Washington DC, an urban community in New Delhi, or the commodity chain of green beans. In short, almost anywhere can be a field, if one can recognize what is interesting about it.

"Going into the field" for the purposes of this paper may thus be considered as much of a process than a place - the act of an anthropologist going on her own to see how theories learned in the academic world play out in practice. In the following discussion, I draw from my own fieldwork experiences working in rural agrarian communities of Northeastern Madagascar. This admittedly gives only one specific perspective on the notion of fieldwork, though it is my hope that those anthropologists working within other types of "fields" may also find the allegories of Borges relevant to their own unique experiences of fieldwork.

\section{The Library of Babel: Encountering the Field}

There are official searchers, inquisitors. I have seen them in the performance of their function: they always arrive extremely tired from their journeys; they speak of a broken stairway which almost killed them; they talk with the librarian of galleries and stairs; sometimes they pick up the nearest volume and leaf through it, looking for infamous words.

- The Library of Babel, p55

In this story, Borges introduces us to a virtually infinite library, also called the Universe. Within its walls, all combinations of all letters exist. There is a problem, however: no one can ever find anything that makes sense. At first, Borges tells us, scholars of all sorts rejoiced at the news that all combinations of letters existed in one place. Logically, this meant that all the great and prophesied works could at last be found. Logistically, however, there was no system in place to sort out what collections of letters were contained in which book, or where such a book could be located within the Library. Some men dedicated their entire lives to systematically examining all the books in one small part of the library, searching for even just a single phrase that seemed to make sense. People perished within the library walls; the number of librarians lessened each year.

It is interesting to substitute the word "ethnographers" for the word "inquisitors" in the above story. It is easy to imagine anthropologists attacking the new world of their field site much as new library recruits attack the books upon the shelves: optimistic that they may find answers, or maybe even one great concept. Yet undertaking ethnographies presents the same challenges as negotiating through the Library of Babel. First, where should one start? Arriving for the first 
time at a field site, anthropologists realize that all the information they may need is there, waiting, but there is so much of it. It is a frustrating task. Like the hapless researchers wandering through the library, anthropologists may also find that "for every sensible line of straightforward statement, there are leagues of senseless cacophonies, verbal jumbles and incoherencies (53)." As with the "imperfect" librarians, one may find herself scaling down from coming up with the perfect sentence, to trying to find even one word that makes sense (52).

Another parallel offered by the story is that the "mystique" surrounding the Library also exists to a certain extent with the practice of fieldwork - especially for the anthropology "initiate" going "into the field" for the first time (Jackson 1990). Although this is changing today, for much of anthropology's history there was little formal attention within academic curriculums dedicated to explaining techniques for the practice of fieldwork (ibid). As such, anthropology students usually went to the field with little concrete advice on how to negotiate what they were to find. Instead, they were often thrown out into research through a "by-the-seat-of-your-pants" approach armed only with general platitudes from their advisors (Jackson 1990). EvansPritchard, for example, recounted some of the advice he received before going to conduct his own fieldwork, including: be a gentleman, take a daily dose of quinine, and "don't converse with an informant for more than twenty minutes because if you aren't bored by that time he will be (1976:241)."

A further issue often raised about encountering a field site for the first time is how to arrive at your research site with enough - but not too much - prior information about what you may find. In an academic culture that primarily funds preconceived research hypotheses and not "holistic" studies, it is a challenge to maintain a sense of discovery when observing and processing ethnographic experiences. When balancing between informed and preemptive research, Borges' story of Tlon, Uqbar, Orbis Teritus becomes relevant. In it, Borges describes the imaginary community of Rose Crucis - a community created by a German theologian, which ultimately became "a community that others founded later, in imitation of what he had prefigured." (5)

In my own field research, for example, I had framed a research question before leaving that investigated how small-scale vanilla farmers in a community of Northeastern Madagascar were changing their land use practices following the dramatic drop in international vanilla bean prices. When preparing my grant applications before leaving for fieldwork, I cited the studies from other parts of Madagascar that described the various ways farmers were reacting to the change in the vanilla market. I had thus already formed my own narrative of what I would find once I arrived to my fieldsite, and I subsequently remained watchful for people who were changing their vanilla gardens into other types of land use. Indeed I noticed that a few families were doing so. I also, however, noticed that many more families were not converting their vanilla fields into some other form of land use. This observation caused me to step back and reframe my question, which ultimately emerged as a more interesting one: why were people continuing to plant vanilla in this one community, despite economic incentives to do otherwise? Was there something else going on there that differed from the other communities described in the academic literature? I thus realized the importance of being able to shift my research questions and narrative depending on what I was observing once in the field, in order not to configure my observations into a preconceived framework. 


\section{Pierre Menard, Author of the Quixote: Ethnography through the Stories of Others}

Pierre Menard did not want to compose another Quixote- which is easy- but the Quixote itself. Needless to say, he never contemplated a mechanical transcription of the original; he did not propose to copy it. His admirable intention was to produce a few pages which would coincide-word for word and line for line-with those of Miguel de Cervantes.

- Pierre Menard, author of the Quixote, p39

In this story, Borges introduces us to Pierre Menard and his mission to recreate Don Quixote word for word. This task, as the above passage mentions, was not the same as transcribing the novel. It was to reinvent it entirely, but in a way that would keep it absolutely faithful in content to the original. To accomplish his goal, Menard first considered actually becoming Cervantes, the original author. He thus pondered a course of action that would involve learning Spanish, becoming Catholic, fighting the Moors, and forgetting European history. Menard rejected this method, however, for being too simple. Instead, he decided to keep his own identity, thus undertaking a much more difficult task: to "reach the Quixote through the experiences of Pierre Menard." (40) And he succeeded, recreating small segments of Don Quixote word for word.

Borges then makes a very interesting observation. He notes that: "Cervantes' text and Menard's are verbally identical, but the second is almost infinitely richer." (42) This story thus presents an allegory both for the practice of fieldwork, especially for participant observation, and for composing ethnographies through the stories of others. Beginning with Malinowski's famous goal of seeing things from the native's point of view, anthropologists have embraced participant observation as a way of understanding the people with whom they work. Yet, the tension remains between immersion and keeping one's own voice - between balancing "objective" observation with more "subjective" interpretations.

Ultimately, there are always barriers to complete immersion - we can never become Cervantes, really. Even works which present word-for-word transcripts of conversations or interviews require some sort of filter - the anthropologist is always in the background, ordering, selecting, and editing whose words will be included and whose will be excluded. Evans-Pritchard sums up this relationship neatly by noting that "what one brings out of a field-study largely depends on what one brings to it." (1976:241) Thus, the ethnographer's presence is never erased in fieldwork. Instead, ethnographic "data are really our own constructions of other people's constructions of what they and their compatriots are up to." (Geertz 1973:9) As both writers and readers, anthropologists can be aware of these extra layers, embracing them for the additional richness they offer, instead of attempting the nearly impossible pursuit of removing them entirely.

In addition to his story of Don Quixote, another theme that occupied Borges can also be used in understanding the interactions between a researcher and the people she is working with: that of two mirrors facing one another. ${ }^{3}$ The image of the mirror is present in many of Borges' stories (including in the Library of Babel which states that the library made use of mirrors to give the 
patrons a sense of the infinite). In one sense, the ethnographer, as an outsider, can never get an absolutely comprehensive sense of the place she is working, but rather only "second and third order" interpretations that are refracted through her own cultural and epistemological lenses (Geertz 1973:15).

As with the double-reflection of two mirrors facing each other, the ethnographer and her subjects also continuously reflect the experiences and realities of one another. Rather than make the pursuit of knowledge hopeless, however, such interactions and collaborations between an anthropologist and her "informants" can lead to more interesting interpretations. As with Pierre Mernard and Don Quixote, recognizing and embracing the complexity inherent in telling stories of others often results in a richer narrative.

\section{Funes the Memorious: On Sorting through Data}

Not only was it difficult for him to comprehend that the generic symbol dog embraces so many unlikely individuals of diverse size and form; it bothered him that the dog at three fourteen (seen from the side) should have the same name as the dog at three fifteen (seen from the front).

- Funes the Memorious, p65

In this story, Borges introduces the character Ireneo Funes, who was thrown off his horse one afternoon and became paralyzed. In the process, the accident gave him enhanced powers of perception and a perfect memory. Funes could now remember every experience he had ever had in exact and unwavering detail. As Borges writes, Funes "remembered not only every leaf of every tree of every wood, but also every one of the times he had perceived or imaged it." (65)

Though Funes' new powers offered him some advantages, they also presented him with some unique challenges. How could he manage and sort through such piles of memories? He was able to construct a whole day, for example, but it took him a whole day to do so. Trying to arrange his memories into a useful framework proved difficult, as he lamented that "by the hour of his death he would not even have finished classifying all the memories of his childhood." (65) Thus, Borges suggests to the reader that "to think is to forget differences, generalize, make abstractions." (66) Funes' world, which consisted only of details, therefore offered no insight how to place his discrete experiences into larger frameworks or theories.

This particular story may resonate with the experience of an anthropologist back from the field, sitting at a computer surrounded by fieldnotes waiting to be coded and categorized. Transcribing notes into some sort of general framework presents a real challenge in the practice of writing ethnography. Balancing detail and theory in ethnography is daunting, and also taps into questions on the appropriateness of scaling-up field observations to other regions and issues.

As details compile in the anthropologist's daily record, one may therefore feel a bit like Funes: overwhelmed with endless potential data with little insight onto which can be justifiably condensed under similar headings. In my work in Madagascar, for example, I wonder: How can Armand the vanilla farmer's statements made on August $5^{\text {th }}$ at three o'clock be reconciled with 
those of Armand the vanilla farmer a week later? What relationship does the vanilla garden (intercropped with coffee) on this side of the street have with the vanilla garden (intercropped with clove trees) on the other side of the street? When can one stop taking notes and say something about anything? In short, how much is enough fieldwork?

Just as Funes, immersed only in the minutia of recording every small observation was unable to prioritize which observations were most helpful in categorizing his experiences, an anthropologist in the field may have difficulties recognizing which of the many observations of daily life may hold the most promise for further attention. In my fieldwork, for example, I find myself alert in every conversation: will this chance remark be useful later on? Should I write down every conversation I have? How will I know what will be relevant to my work later on? How will I know what I will most want to remember once I return from the field?

Overall, just as Funes felt "cursed" by his exhaustive memory, anthropologists often express a mixed relationship to their exhaustive fieldnotes- as Jackson notes in her discussion of the interviews she conducted with a spectrum of anthropologists. She reports that anthropologists often describe their fieldnotes by "using familiar words from the anthropological lexicon such as sacred, taboo, fetish, exorcise, and ritual." (1990:5) They also confess to feeling "oppressed" by their notes, sitting there in boxes waited to be coded and revisited. The anthropologist Sanjek has written on the abundance of stories which circulate about anthropological fieldnotes which were destroyed by fire, shipwrecks, and war (1990:34-36). In fact, Sanjek (1980) notes the suggestions by some anthropologists that those anthropologists who lose their fieldnotes may ultimately be better off. Such sentiment is epitomized by famous case of Edmund Leach, who, freed from his notes which were lost as result of an enemy action, was able to generalize broadly in writing his "Political Systems of Highland Burma (1990:37). ${ }^{4}$

\section{Death and the Compass: Going Home}

He had very nearly deciphered the problem; mere circumstances, reality (names... faces...) hardly interested him now. He wanted to travel a bit, he wanted to rest from three months of sedentary investigation... The mystery appeared almost crystalline to him no; he was mortified to have dedicated a hundred days to it.

- Death and the Compass, $p 20$

This passage describes the activities of the detective Lönnrot, a "pure reasoner" who also had "something of the adventurer in him, and even a little of the gambler." (76) In the story, the detective seemingly solves a great mystery of a triple murder- a puzzle that had been plaguing him for 100 days. Lönnrot deduced the solution by focusing on the "secret morphology" of the crime, which he found through a combination of mapping and discourse analysis. He found (with the help of an anonymous "informant") that taken collectively the data exhibited "a symmetry in time... [and a] symmetry in space as well...." (82) While solving the mystery, Lönnrot was most intrigued with the meanings behind the actions of the murderer, as opposed to focusing only on the actions themselves. As he explains to the more practical-minded Inspector, "here we have a dead rabbi; I would prefer a purely rabbinical explanation, not the imaginary mischances of an imaginary robber." (77) 
The passage quoted at the beginning of this section reflects Lönnrot's thoughts after solving the great puzzle of the triple murders. Such thoughts may reflect part of what runs through anthropologists' heads while packing their bags to return home from their field research. Although many questions still remain, anthropologists at this point may feel ready to begin sorting through their experiences and writing up their ideas.

As reflected in the above quote, once the detective feels he had solved the problem, names and faces seemed to lose their salience. Similarly, back at university, deadlines looming, it can be challenging to recreate the field experience in all its texture and detail. In scaling between the minutiae of the daily life at the fieldsite and the broad theories of articles, we may be tempted to gloss over messy detail in favor of a satisfying theory. While leaving the field "behind" may be most relevant to those working in far-away sites, even for anthropologists working closer for home, some of the same challenges may remain when negotiating between the field experience and writing up research: how, for example, does one balance between writing about an informant who has become a close friend? How can one convey the energy and complexity of a site within the structure of an academic article?

Borges' detective offers another interesting twist for the reader: it turns out, after all, that the detective had entirely misunderstood the situation. Far from figuring out the secret to a mystery, Lönnrot was actually being manipulated by the people he was tracking, who anticipated the information he was looking for and tailored their "clues" accordingly. A parallel to this dynamic may arise in field research as well: who is really defining the situation, who is leading whom, and who is the "gatekeeper" deciding which information is told and which withheld?

If there is a case of an anthropologist being "misled" by informants, this in itself provides an interesting puzzle: what was the purpose of the misdirection? What can one learn from what is kept hidden from whom? As the anthropologist Bloch notes, examining the "systems by which we conceal the world" are often as important to examine as the "systems by which we know the world." Indeed, he concludes, systems of knowing are often simultaneously systems of concealing (1977). Overall, then, the detective learns that knowing what one does not understand about a situation is just as valuable as what one thinks he does understand.

Finally, in Borges' story of the detective, it is interesting that although he misinterpreted the situation, Lönnrot's position as the expert may confer to him the ability to create the "official" record of the situation. Similarly, the image of the anthropologist writing up fieldnotes taps into the larger power dynamics established through the very act of recording information. Especially working in communities which may not be very comfortable with literacy, the act of writing itself often becomes encoded with associations of power and oppression (Skaria 1996). Particularly working in postcolonial societies, the person who is writing things down is often connected to the person who is able to create, circulate, or modify an official record (ibid).

In an attempt to partly even out this divide, anthropologists are today often encouraged to give a copy of their written work to the communities where they studied. The appropriate extent and nature of the information transfer between ethnographers and the communities where they work remains a subject of debate today, as anthropologists walk the ill-defined and controversial line between moral "engagement" and more direct "activism" (Hale 2008; Kirsch 2002). 


\section{Summary}

The four stories I briefly highlighted above offer anthropologists allegories for thinking about ethnographic practices. In the story of the library inquisitors: an allegory for making sense of seemingly limitless, but unordered, information. In the story of rewriting Don Quixote: how to both write about and through the experiences of others. With poor Funes cursed by perfect memory: how both remembering and forgetting is required for making sense of things. And finally, in Death and the Compass, to realize the importance both what one does and does not understand about the places where one works.

Particularly helpful in understanding ethnographic practices is the metaphor of labyrinths that Borges implements in many of his stories. These mazes arrange themselves into circular patterns, and necessitate thoughtful navigation replete with false starts, sudden barriers, and a logic that seems to fold back upon itself. For Borges, we often construct our own labyrinths, and then forget to leave ourselves a trail of breadcrumbs so that we can escape again. Wandering lost through aisles of the library or footpaths of the jungle, we may at times feel overwhelmed by the information around us. Facing the fieldnotes we ourselves created, trying to reason through a theoretical tautology, or realizing once we are back home that there was a crucial question we forgot to ask: such common fieldwork experiences reflect dimensions of Borges' labyrinths.

Borges also, however, reminds us that the most complicated and paradoxical situations hold keys to deeper truths. It is often what we do not at first understand - the observation that does not fit neatly into our preformed narratives - that ultimately provides us with the best fodder for thought. It is by working through such labyrinths, then, that we may continue to strive towards the chance for deeper understanding and insight.

\section{References}

Borges, J. 1964. Labyrinths: Selected stories and other writings. New York: New Directions Publishing Company.

Clifford, J. 1986. Writing Culture: Poetics and Politics of Ethnography. Berkeley: University of California Press.

Coronil, F. 2001. Smelling Like a Market. The American Historical Review February 2001. Evans-Prichard, E.E. 1976. Appendix: Some Reminiscences and Reflections on Fieldwork. In Witchcraft, Oracles and Magic among the Azande. Oxford: University of Oxford.

Foucault, M. 1994. The Order of Things: An Archeology of the Human Sciences. New York: Vintage Publications.

Geertz, C. 1973. The Interpretation of Cultures. New York: Basic Book Publishers. Hale, Charles R. 2008. Engaging Contradictions: Theory, Politics, and Methods of Activist Scholarship. University of California Press. 
Jackson, J. 1990. 'I Am a Fieldnote': Fieldnotes as a Symbol of Professional Identity. In Roger Sanjek (ed). Fieldnotes: The Makings of Anthropology. Ithaca: Cornell University Press.pp3-33. Kirsch, Stuart. 2002. Anthropology and Advocacy: A Case Study of the Campaign Against the OK Tedi Mine. Critique of Anthropology22(2):175-200.

Malinowski, B. 1966[1922]. Argonauts of the Western Pacific: An Account of Native Enterprise and Adventure in the Archipelagoes of Melanesian New Guinea. New York: Dutton.

Marcus, George E. and Dick Cushman. 1982. Ethnographies as Texts. Annual Review of Anthropology 11:25-69.

Ortner, S. 1984. Theory in Anthropology Since the Sixties. Comparative Studies in Society and History 26(1):126-66.

Sanjek, R. 1990. Fire, Loss and the Sorcerer's Apprentice. in Roger Sanjek (ed). Fieldnotes: The Makings of Anthropology. Ithaca: Cornell University Press.pp34-44.

Sivaramakrishnan, K. and Agrawal, A. 2003. Regional Modernities: The Cultural Politics of Development in India. Stanford: Stanford University Press.

Skaria, A. 1996. Writing, orality, and power in the Dangs. In Subaltern Studies IX: Writings on South Asian History and Society, edited by Shahid Amin and Dipesh Chakrabarty. New Delhi: Oxford University Press. Pp. 13-58.

\section{Acknowledgements}

I would like to thank the organizers of the Expanding Boundaries conference, especially Robert McKenzie and Mira Mohsini, for facilitating this opportunity and discussion. I am also grateful to the Schwartz Conference Fund through the Department of Anthropology at Yale University for their travel support, which allowed me to attend the conference. I would also like to thank two anonymous reviewers, as well as the members of the Social Ecology Doctoral Lab at Yale University, who provided useful feedback on earlier versions of this paper.

\section{About the Author}

Sarah Rae Osterhoudt is a PhD candidate in the Department of Anthropology at Yale University. She can be contacted at sarah.osterhoudt(AT)yale.edu.

\section{Endnotes}

\footnotetext{
${ }^{1}$ Throughout this discussion, quotes from Borges are taken from his Labyrinths: Selected Stories and Other Writings. New York: New Directions Publishing Corporation. 1964.

${ }^{2}$ I am grateful to Mike McGovern and to Ruth Goldstein for pointing out these connections.

${ }^{3}$ This preoccupation of Borges was pointed out to me by Adrian Cerezo.
} 
${ }^{4}$ See also the work The Remembered Village by M. S. Srinivas.

${ }^{5}$ Though I am in no way advocating trying to lose one's fieldnotes 